УДК 622.413 .4

\title{
СПОСОБЫ НОРМАЛИЗАЦИИ МИКРОКЛИМАТА В ГЛУБОКИХ ПРОТЯЖЕННЫХ ТУПИКОВЫХ ВЫРАБОТКАХ
}

\author{
Ольховский Дмитрий Владимирович 1 , \\ demexez@gmail.com
}

\author{
Зайцев Артем Вячеславович1, \\ aerolog.artem@gmail.com
}

Шалимов Андрей Владимирович1, shalimovav@mail.ru

\author{
Давыдов Андрей Александрович², \\ Davydovaa@nornik.ru \\ 1 Горный институт уральского отделения российской академии наук, \\ Россия, 614007, г. Пермь, ул. Сибирская, 78а. \\ 2 ПАО «ГМК "Норильский Никель"», \\ Россия, 123100, г. Москва, 1-й Красногвардейский проезд, 15.
}

\begin{abstract}
Актуальность исследования обусловлена необходимостью рудников решать новые проблемы нормализации микроклимата, возникающие при проходке все более глубоких и нагретых породных массивов протяженными тупиковыми выработками. Цель: определить эффрективность различных способов нормализации микроклимата в забое разведочной выработки-2 ПАО «ГМК "Норильский никель"».

Объекты: геологоразведочная выработка-2 ПАО «ГМК "Норильский никель"».

Методы: численное моделирование тепломассопереноса в атмосфрере горной выработки, проведение сравнительного анализа результатов моделирования.

Результаты. Рассмотрены способы нормализации микроклимата в глубоких протяженных тупиковых выработках, их особенности, преимущества и недостатки. Представлена математическая модель тепломассопереноса в атмосфрере горной выработки с вентиляционным трубопроводом, учитьвающая конвективный и лучистьй теплообмен. Представлены результаты расчета различных способов снижения температуры воздуха, подаваемого в забой геологоразведочной выработки, строящейся на медно-никелевом руднике компании ПАО «ГМК "Норильский никель"». Проведен сравнительный анализ различных горнотехнических и теплотехнических мероприятий по снижению температуры воздуха в забое выработки до значений, допустимых согласно Правилам безопасности. Выявлено, что увеличение объема подачи воздуха не позволяет значительно снизить температуру в забое. Применение теплоизолированного вентиляционного трубопровода существенно снижает температуру подаваемого в забой воздуха, но её значение по-прежнему остается выше допустимых значений. Показано, что использование камеры орошения позволяет обеспечить допустимую температуру воздуха в зимний период, но не позволяет обеспечить её в летний период. Наиболее универсальным, эфффективным, но дорогостоящим способом снижения температуры воздуха является применение подземных систем кондиционирования воздуха на базе парокомпрессионных машин.
\end{abstract}

\footnotetext{
Ключевые слова:

Тупиковая выработка, глубокий рудник, микроклимат, орошение, теплоизоляция, кондиционирование, вентиляционный трубопровод.
}

\section{Введение}

Увеличение глубины ведения горных работ ведет к росту температуры вскрываемого породного массива, который в свою очередь приводит к более интенсивному нагреву воздуха, двигающегося по выработкам [1-4]. Помимо этого, применение все более высокопроизводительной техники ведет к увеличению тепловыделений в атмосферу горных выработок [5-7]. В результате температура воздуха в горных выработках может существенно превышать предельнодопустимые значения - возникает вопрос о разработке мероприятий по её снижению.

Особую сложность представляют новые тупиковые выработки большой протяженности, которые прокладывают на больших глубинах. Помимо обеспечения требуемым количеством воздуха забоя, расположенного на расстоянии нескольких километров от точки забора свежего воздуха, необходимо также обеспечить температуру подаваемого воздуха не выше предельно допустимой $\left(+26{ }^{\circ} \mathrm{C}\right)[8]$, т. к. воздух, двигаясь по вентиляционному трубопроводу, проложенному по тупиковой выработке, сильно нагревается в результате теплообмена с исходящей струей воздуха, двигающейся по самой выработке, и горячим горным массивом. На данный момент ПАО «ГМК "Норильский никель"» ведет проходку геологоразведочной выработки-2 (РВ-2) на руднике «Скалистый», которая должна соединить вентиляционный ствол № 10 (далее ВС-10) и скипо-клетьевой ствол № 1 (далее СКС-1) (рис. 1). Общая длина выработки будет составлять порядка 1830 м, средняя глубина, на которой ведутся работы, составляет 1943 м, а температура нетронутого породного массива в месте проходки выработки составляет $52{ }^{\circ} \mathrm{C}$. 


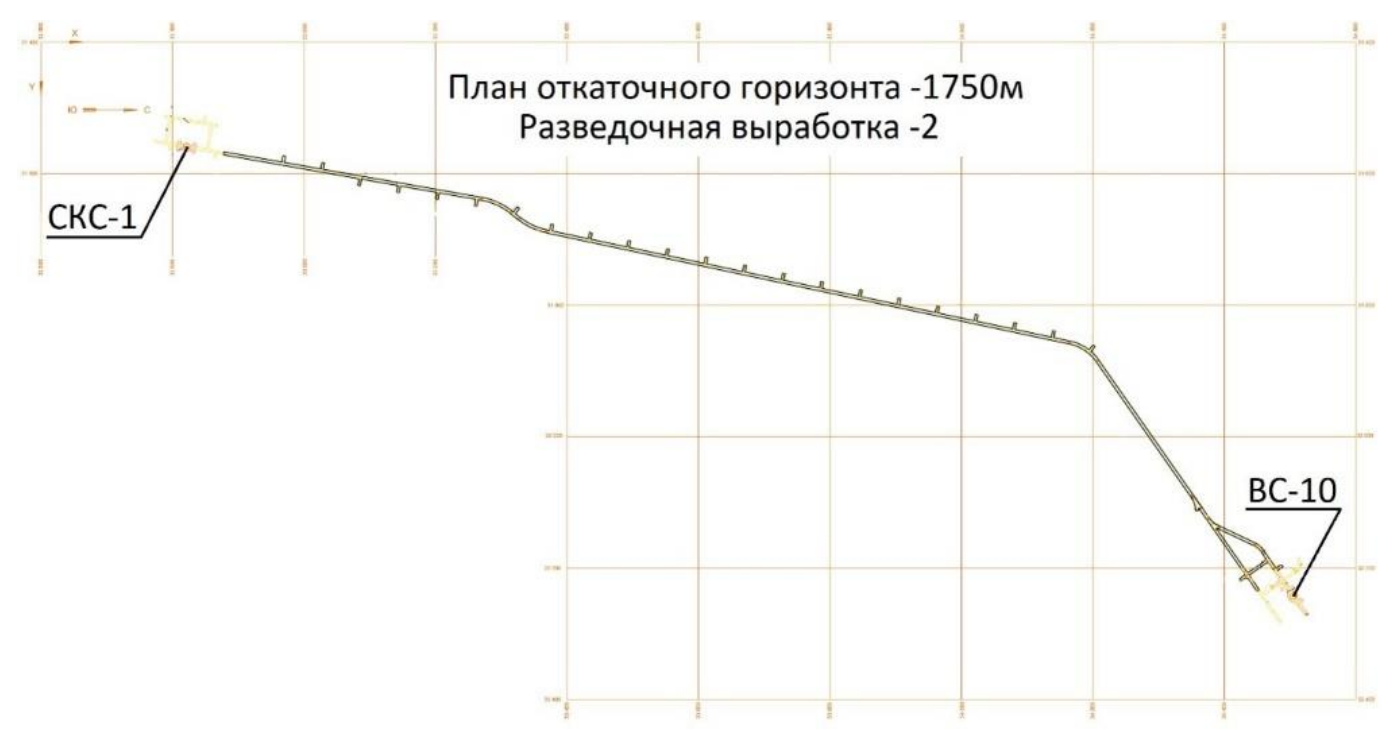

Рис. 1. План выработки РВ-2

Fig. 1. Layout exploration drift (ED-2)

Проветривание выработки осуществляется вентиляторами, расположенными на поверхности, они подают воздух по вентиляционным трубопроводам, проложенным в стволе ВС-10, в объеме $20 \mathrm{~m}^{3} / \mathrm{c}$. Особенностью на данном объекте является температура воздуха, подаваемого на горизонт выработки РВ-2, которая колеблется строго в диапазоне $20-21{ }^{\circ} \mathrm{C}$ вне зависимости от периода года и температуры воздуха, подаваемого в ствол $[9,10]$. Это происходит из-за того, что через ствол ВС-10 удаляется воздух из шахты «Верхняя» с горизонта 980 м, который имеет температуру $22,5^{\circ} \mathrm{C}$ и высокую относительную влажность $76 \%$, - поднимаясь по стволу, воздух охлаждается до температуры $15,8^{\circ} \mathrm{C}$ и проходит точку росы, происходит обильная конденсация влаги, которая в виде капель и струй по стенкам опускается по стволу [11]. Температура конденсируемой влаги равна температуре точки росы, а объем достаточно большой, чтобы охлаждать воздух в вентиляционных трубопроводах по всей его длине, в результате чего температура воздуха из трубопровода на сопряжении с горизонтом 1750 м стабильно держится на уровне $20-21^{\circ} \mathrm{C}$.

Далее этот воздух подается в забой по вентиляционным трубопроводам, проложенным вдоль РВ-2. По мере проходки выработки и увеличения длины вентиляционного трубопровода для подачи требуемого количества воздуха будут последовательно установлены два вентилятора местного проветривания, которые за счет своей работы увеличат температуру подаваемого воздуха. В результате работы вентиляторов местного проветривания и нагрева воздуха внутри вентиляционного трубопровода от теплообмена с исходящей воздушной струей и горным массивом в выработке температура воздуха, подаваемого в забой, будет превышать предельно допустимую температуру и ведение работ может быть остановлено.

Целью настоящей статьи является анализ способов нормализации микроклимата в рабочих зонах забоев протяженных тупиковых выработок на большой глубине с учетом их особенностей.

\section{Способы нормализации микроклимата} в забое глубоких и протяженных выработок

По мере движения воздуха по вентиляционному трубопроводу в выработке происходит его нагрев за счет конвективного теплообмена с движущейся по выработке исходящей струей через стенку вентиляционного трубопровода. Интенсивность нагрева воздуха внутри вентиляционного трубопровода зависит от двух основных факторов, на которые можно повлиять для снижения температуры воздуха, подаваемого в забой: это скорость движения воздуха внутри трубопровода и термическое сопротивление стенки трубопровода. При этом скорость движения воздуха в самой выработке здесь как отдельный фактор не берется в расчет, так как она определяется скоростью движения воздуха внутри воздуховода. При увеличении скорости движения воздуха (увеличения объема подачи) и увеличении термического сопротивления стенки (нанесения слоя теплоизоляции) интенсивность нагрева воздуха внутри трубопровода уменьшается, в результате температура воздуха, подаваемого в забой, может быть снижена. Эти способы представляются наименее трудозатратными.

Помимо этого, для снижения температуры воздуха, подаваемого в забой, возможно применение систем орошения воздуха. Поскольку воздух подается с поверхности, где его влагосодержание большую часть года остается незначительной [12], и по мере движения по вентиляционным трубопроводам нигде напрямую не контактирует с водой, имеется возможность охлаждения его непосредственно перед забоем за счет испарения в воздухе распыленной в камере орошения воды. Такие системы считаются относительно простыми и не требующими больших капитальных и эксплуатационных затрат, однако их эффективность сильно зависит от внешних факторов, таких как температура и влагосодержание воздуха на поверхности, герметичность вентиляционных трубопроводов, проходящих по стволу. Таких недостатков лишены систе- 
мы кондиционирования, однако стоимость их установки и эксплуатации значительно выше, чем у предложенных ранее способов.

\section{Модель тепломассопереноса в выработке и вентиляционном трубопроводе}

Для оценки способов охлаждения воздуха, подаваемого в забой, необходимо определять его температуру при различных условиях. Для этого была построена математическая модель тепломассопереноса [13] в воздушном потоке внутри вентиляционного трубопровода, учитывающая конвективный и лучистый механизмы теплообмена в системе «воздух в трубопроводе - стенка трубопровода - воздух в выработке - породный массив», а также нагрев воздуха от работы вентиляторов местного проветривания. Для определения температуры воздуха по длине трубопровода можно выделить на расстоянии $x$ от начала трубопровода элементарный участок длиной $d x$ и составить для него уравнение теплового баланса:

$$
\frac{d q_{1}}{d t}=w_{1}+q_{0} \delta\left(x-x_{0}\right)
$$

или в более развернутом виде с учетом стационарности тепломассопереноса:

$$
\begin{aligned}
G_{1} \cdot c_{p} & \cdot \frac{d T_{1}}{d x}=k_{w i} \cdot\left(T_{w o}-T_{1}\right) \cdot \pi+ \\
& +q_{0} \cdot \delta\left(x-x_{0}\right),
\end{aligned}
$$

где $q_{1}$ - теплосодержание малого объема воздуха $S_{1} d x$ в вентиляционном трубопроводе Дж; $S_{1}-$ поперечное сечение проточной области трубопровода, м $^{2} ; w_{1}$ тепловой поток к малому объему воздуха от стенки трубопровода на отрезке длиной $d x$, Вт; $q_{0}$ - мощность точечного теплового источника (вентилятора), Дж; $\delta\left(x-x_{0}\right)$ - дельта функция Дирака; $x$ - координата по длине горной выработки, м; $x_{1}-$ координата точечного теплового источника, м; $G_{1}$ - массовый расход воздуха внутри вентиляционного трубопровода, кг/c; $c_{p}-$ удельная теплоемкость воздуха, Дж/(кг $\left.{ }^{\circ} \mathrm{C}\right) ; T$ - температура воздуха в вентиляционном трубопроводе, ${ }^{\circ} \mathrm{C} ; T_{\text {wo }}$ - температура внешней поверхности стенки вентиляционного трубопровода, ${ }^{\circ} \mathrm{C} ; \mathrm{T}_{1}$ - температура воздуха внутри вентиляционного трубопровода, ${ }^{\circ} \mathrm{C} ; \pi=3,14$ - математическая постоянная, равная отношению длины окружности к её диаметру; $k_{w i}$ - линейный коэффициент теплопередачи через стенку трубопровода и пограничный слой воздушного потока на внутренней границе трубопровода, $\mathrm{BT} /\left(\mathrm{м}^{\circ}{ }^{\circ} \mathrm{C}\right)$.

Коэффициент $k_{w i}$ определяется по формуле:

$$
k_{w i}=\frac{1}{\frac{1}{a_{\text {in }} d_{\text {in }}}+\frac{1}{2 \lambda_{w}} \ln \frac{d_{\text {out }}}{d_{\text {in }}}},
$$

где $a_{i n}$ - коэффициент теплоотдачи воздуха в пограничном слое на внутренней стенке вентиляционного трубопровода, Вт/(м $\left.{ }^{2}{ }^{\circ} \mathrm{C}\right) ; d_{\text {in }}$ - внутренний диаметр вентиляционного трубопровода, м; $\lambda_{w}-$ коэффициент теплопроводности стенки вентиляционного трубопровода, Вт $/\left(\mathrm{м}^{\circ} \mathrm{C}\right) ; d_{\text {out }}-$ внешний диаметр вентиляционного трубопровода, м.
Для определения температуры воздуха в выработке составляется еще одно уравнение теплового баланса:

$$
\begin{gathered}
\frac{d q_{2}}{d t}=w_{2}+w_{3}, \\
G_{\text {out }} \cdot c_{p} \cdot \frac{d T_{2}}{d x}=\left(T_{\text {wo }}-T_{2}\right) \cdot a_{\text {wo }} \cdot P_{\text {wo }}+ \\
+\left(T_{\text {out }}-T_{r}\right) \cdot a_{r} \cdot P_{r},
\end{gathered}
$$

где $q_{2}$ - теплосодержание малого объема воздуха $S_{2} d x$ в выработке, Дж; $S_{2}$ - поперечное сечение проточной области выработки, м²; $w_{2}$ - тепловой поток от малого объема воздуха к стенке трубопровода на отрезке длиной $d x$, Вт; $w_{3}$ - тепловой поток от окружающего породного массива к малому объему воздуха на отрезке длиной $d x$, Вт; $G_{2}$ - массовый расход воздуха, двигающегося по выработке, кг/с; $T_{2}$ - температура воздуха в выработке, ${ }^{\circ} \mathrm{C} ; a_{w o}-$ коэффициент теплоотдачи воздуха снаружи вентиляционного трубопровода, Вт/(м $\left.{ }^{2} \cdot{ }^{\circ} \mathrm{C}\right) ; P_{w o}-$ периметр наружной стенки трубопровода, м; $T_{w o}$ - температура внешней стенки трубопровода, ${ }^{\circ} \mathrm{C} ; a_{r}-$ коэффициент теплоотдачи воздуха на поверхности выработки, Вт/(м $\left.{ }^{2} \cdot{ }^{\circ} \mathrm{C}\right)$; $P_{r}$ - периметр горной выработки, м; $T_{r}$ - температура окружающего породного массива, ${ }^{\circ} \mathrm{C}$.

Коэффициент теплоотдачи между воздухом и горной породой определяется по формуле Щербаня [14]:

$$
a_{r}=3,4 \cdot \frac{V_{2}^{0,8}}{d_{r}^{0,2}}, \text { Вт } /\left(\mathrm{M}^{2} \cdot{ }^{\circ} \mathrm{C}\right),
$$

где $V_{2}-$ скорость воздуха внутри выработки, м/с; $d_{r}-$ эквивалентный диаметр выработки, м.

Коэффициент теплоотдачи воздуха в пограничном слое на внутренней стенке вентиляционного трубопровода определяется исходя из безразмерного комплекса (числа Нуссельта $\mathrm{Nu}$ ) по формуле:

$$
a_{i n}=\frac{\lambda}{d_{w i}} \cdot \mathrm{Nu}, \mathrm{BT} /\left(\mathrm{M}^{2} \cdot{ }^{\circ} \mathrm{C}\right),
$$

где $\lambda$ - коэффициент теплопроводности воздуха, $\mathrm{BT} /\left(\mathrm{M}^{\circ}{ }^{\circ} \mathrm{C}\right)$;

Число Нуссельта определяется по эмпирической формуле Михеева [15]:

$$
\mathrm{Nu}=0,021 \cdot \operatorname{Pr}^{0,8} \cdot \operatorname{Re}_{1}^{0,43},
$$

где $\operatorname{Pr}$ - число Прандтля, которое для воздуха в турбулентном режиме течения принимается равным 0,71 ; $\mathrm{Re}-$ число Рейнольдса, которое определяется по формуле:

$$
\operatorname{Re}_{1}=\frac{\mathrm{V}_{1} \cdot d_{w i}}{v},
$$

где $V_{1}$ - скорость воздуха в вентиляционном трубопроводе, м/c; $v$ - кинематическая вязкость воздуха, определяется по справочным материалам [15], $\mathrm{m}^{2} / \mathrm{c}$.

Коэффициент теплоотдачи снаружи вентиляционного трубопровода $\left(a_{w o}\right)$ определяется также по формуле (3), но число Нуссельта находят по другой формуле, соответствующей случаю параллельного обтекания потоком круглой трубы:

$$
\mathrm{Nu}=0,037 \cdot \operatorname{Pr}^{0,43} \cdot \mathrm{Re}_{2}^{0,8} .
$$

В качестве числа Прандтля в (5) также принимается величина 0,71, а величина числа Рейнольдса определяется по формуле, аналогичной (4): 


$$
\operatorname{Re}_{2}=\frac{\mathrm{V}_{2} \cdot d_{w o}}{v},
$$

где $V_{2}$ - скорость воздуха в выработке, м/с;

Для определения температуры внешней поверхности стенки трубопровода необходимо составить третье уравнение теплового баланса для малого объема воздуха, в котором будет учтен лучистый теплообмен между поверхностью трубопровода и стенками выработки:

$$
\begin{gathered}
\frac{\left(T_{w o}-T_{1}\right) \cdot \pi}{\frac{1}{a_{\text {in }} \cdot d_{\text {in }}}+\frac{1}{2 \lambda_{\text {cr }}} \log \frac{d_{\text {out }}}{d_{\text {in }}}}= \\
=\left(T_{2}-T_{w o}\right) \cdot a_{w o} \cdot P_{w o}+ \\
+\varepsilon \cdot C_{0} \cdot\left[\left(\frac{T_{r}+273}{100}\right)^{4}-\left(\frac{T_{w o}+273}{100}\right)^{4}\right] \cdot P_{w o},
\end{gathered}
$$

где $\varepsilon$ - степень черноты поверхности трубопровода, определяется по справочникам; $C_{0}=5,67$ - коэффициент излучения абсолютно черного тела.

Далее численно решается система уравнений (1), (2), (6) и строится график зависимости температуры от длины вентиляционного трубопровода при следующих граничных условиях:

$$
\begin{aligned}
& T_{1}(0)=T_{u l}, \\
& T_{2}(L)=T_{d e},
\end{aligned}
$$

где $T_{u l}$ - замеренная температура воздуха, подаваемого на горизонт, ${ }^{\circ} \mathrm{C}$. В рассматриваемом случае $T_{\text {гор }}$ $=21{ }^{\circ} \mathrm{C} ; L-$ протяженность рассматриваемого участка, м. В рассматриваемом случае $L=1830 \mathrm{м} ; T_{d e}-$ температура воздуха в забое, ${ }^{\circ} \mathrm{C}$.

Для упрощения расчета в модели были приняты следующие допущения:

- поверхность вентиляционного трубопровода однородна;

- теплоемкость воздуха принята постоянной;

- плотность воздуха по всей длине трубопровода принимается постоянной;

- температура поверхности породного массива принимается постоянной и одинаковой по всей длине выработки.

\section{Увеличение подачи воздуха}

Наиболее простым способом снижения температуры воздуха, подаваемого в забой, является увеличение объема подачи свежего воздуха, однако ввиду невозможности замены поверхностных вентиляционных установок и вентиляционных труб, идущих по стволу, увеличение подачи возможно только за счет уменьшения утечек воздуха. Согласно техническим решениям, которые были заложены при проектировании PB-2, при максимальном удалении (1830 м) забоя выработки от ствола ВС-10, применении стальных вентиляционных трубопроводов и подаче на горизонт $20 \mathrm{~m}^{3} / \mathrm{c}$ в забой будет подаваться только $12,3 \mathrm{~m}^{3} / \mathrm{c}$, остальная часть воздуха будет потеряна в виде утечек [16]. Увеличить объем подачи воздуха в забой за счет снижения утечек в трубопроводах выработки можно за счет применения высокопрочных и не изношенных гибких вентиляционных трубопроводов или гермети- зации стальных. Так, для высокопрочных гибких вентиляционных трубопроводов Protan AS, согласно паспортным характеристикам, утечки при длине 1800 м составят $15 \%$ и при подаче $20 \mathrm{~m}^{3} / \mathrm{c}$ на горизонт до забоя выработки дойдет $17,4 \mathrm{~m}^{3} / \mathrm{c}$.

Для оценки снижения температуры воздуха, подаваемого в забой, от увеличения объема подаваемого воздуха были построены графики температуры воздуха внутри вентиляционного трубопровода при данных расходах (рис. 2).

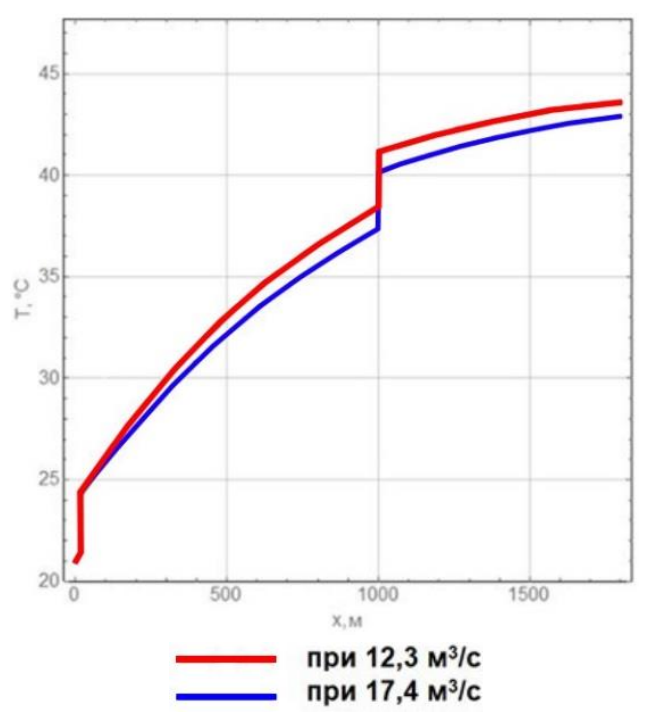

Pис. 2. График температуры воздуха внутри вентиляиионного трубопровода в зависимости от объема подачи воздуха в забой

Fig. 2. Graph of dependence of the air temperature inside the air duct on the flow rate air supply to the face drifts

Скачки температуры в начале графика и на удалении в 1000 м от ствола ВС-10 показывают зависимость роста температуры от работы вентиляторов местного проветривания. В результате нагрева воздуха от работы вентиляторов и теплообмена с окружающей средой в выработке температура воздуха, подаваемого в забой при расходе $12,3 \mathrm{~m}^{3} / \mathrm{c}$, составит $43,7{ }^{\circ} \mathrm{C}$. Увеличение подачи воздуха с 12,3 до 17,4 $\mathrm{m}^{3} / \mathrm{c}$ привело к снижению температуры воздуха в забое с 43,7 до $43,0{ }^{\circ} \mathrm{C}$, что на $0,7{ }^{\circ} \mathrm{C}$ ниже и попрежнему значительно превышает предельно допустимую температуру воздуха $26{ }^{\circ} \mathrm{C}$ [8]. В результате можно сделать вывод, что увеличение подачи количества воздуха в забой несущественно влияет на его температуру. Такой незначительный эффект, несмотря на практически полуторакратное увеличение объема подачи воздуха, происходит из-за того, что при увеличении расхода воздуха коэффициент теплоотдачи также увеличивается по закону, который близок к линейному, - это следует из формул (6) и (8).

\section{Применение теплоизолированного трубопровода}

Другим способом снижения температуры воздуха, подаваемого в забой, является снижение теплового влияния исходящей струи воздуха в выработке и лу- 
чистого теплообмена с горным массивом на температуру воздуха в вентиляционном трубопроводе. Это может быть достигнуто путем нанесения слоя теплоизоляции на поверхность трубопровода. Теплоизоляция позволит снизить нагрев от конвективного теплообмена воздуха в вентиляционном трубопроводе с воздухом в горной выработке через стенку трубопровода, а также нагрев от лучистого теплообмена между поверхностью трубопровода и поверхностью породного массива за счет увеличения температуры поверхности трубопровода.

В качестве теплоизоляции могут использоваться маты минераловатные, которые имеют следующие теплотехнические характеристики:

Таблица 1. Теплотехнические характеристики мат минераловатных

Table 1. Burning characteristics of mineral wool insulation

\begin{tabular}{|l|c|c|c|}
\hline $\begin{array}{c}\text { Tеплоизоляция } \\
\text { Insulation }\end{array}$ & $\begin{array}{c}\text { Теплопроводность, } \\
\mathrm{BT} /\left(\mathrm{M} \cdot{ }^{\circ} \mathrm{C}\right) \\
\text { Thermal } \\
\text { conductivity, } \\
\mathrm{W} /\left(\mathrm{m}^{\circ}{ }^{\circ} \mathrm{C}\right)\end{array}$ & $\begin{array}{c}\text { Удельная } \\
\text { теплоемкость, } \\
\left.\text { Дж/(кг }{ }^{\circ} \mathrm{C}\right) \\
\text { Specific thermal } \\
\text { capacity, } \mathrm{J} /\left(\mathrm{kg} \cdot{ }^{\circ} \mathrm{C}\right)\end{array}$ & $\begin{array}{c}\text { Плот- } \\
\text { ность } \\
\mathrm{K \Gamma} / \mathrm{m}^{3} \\
\text { Density, } \\
\mathrm{kg} / \mathrm{m}^{3}\end{array}$ \\
\hline $\begin{array}{l}\text { Maты минера- } \\
\text { ловатные } \\
\begin{array}{l}\text { Mineral wool } \\
\text { insulation }\end{array}\end{array}$ & 0,07 & 840 & 150 \\
\hline
\end{tabular}

Критический диаметр теплоизоляции вентиляционного трубопровода рассчитывается по формуле:

$$
d_{\mathrm{\kappa p}}=\frac{2 \cdot \lambda_{l a}}{a_{w o}}, \mathrm{M},
$$

где $\lambda_{l a}-$ коэффициент теплопроводности теплоизоляции вентиляционного трубопровода, $\mathrm{BT} /\left(\mathrm{M}^{\circ} \mathrm{C}\right)$.

Величина критического диаметра для мат минераловатных в рассматриваемом диапазоне коэффициента теплоотдачи наружной стенки вентиляционного трубопровода $\left(a_{w o}\right) 1-15 \mathrm{BT} /\left(\mathrm{m}^{2} \cdot{ }^{\circ} \mathrm{C}\right)$ составит 0,14 0,0093 м, что существенно ниже диаметра рассматриваемых вентиляционных ставов (1,2 м), поэтому даже минимальное наращивание слоя теплоизоляции является обоснованным с точки зрения уменьшения теплопоступлений.

Расчёт был произведен для четырех толщин слоя теплоизоляции - 20, 50, 100 и 150 мм. Результаты расчета представлены на рис. 3 .

Как видно из рис. 3, 20 и 50 мм теплоизоляционного слоя снижают температуру воздуха, подаваемого в забой выработки, с $43,7^{\circ} \mathrm{C}$, на 6,6 и $10,8^{\circ} \mathrm{C}$ соответственно, дальнейшее наращивание теплоизоляции дает меньшее приращение, так при 100 мм температура воздуха дополнительно снижается еще на $2,5^{\circ} \mathrm{C}$ по сравнению с 50 мм, а при 150 мм - на $1{ }^{\circ} \mathrm{C}$ по сравнению со 100 мм теплоизоляции. При выборе толщины теплоизоляции стоит помнить о том, что наружный диаметр вентиляционного трубопровода возрастает, а следственно для него необходимо больше места в выработке, что может привести к необходимости увеличения сечения выработки.

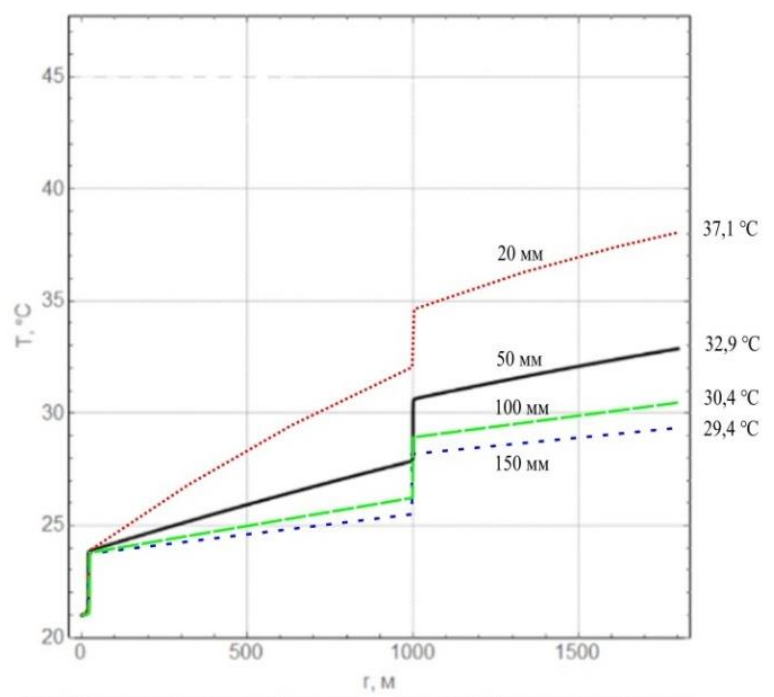

Рис. 3. График температуры воздуха внутри вентиляицонного трубопровода при различной толщиие теплоизолячии

Fig. 3. Graph of dependence of the air temperature inside the air duct on the thermal insulation depth

Стоит отметить, что при использовании теплоизолированных трубопроводов существенную роль в росте температуры воздуха начинают играть вентиляторы местного проветривания, которые, по данным натурных измерений, нагревают воздух на $5-6{ }^{\circ} \mathrm{C}$, в то время как роль конвективного и лучистого теплообмена снижается.

Таким образом, применение теплоизолированных трубопроводов является значительно более эффективным способом снижения температуры воздуха, подаваемого в забой выработки, чем увеличение объема подаваемого воздуха, но по-прежнему недостаточным, так как превышает предельно допустимое значение $26{ }^{\circ} \mathrm{C}$.

\section{Применение оросителей воздуха}

Одним из способов охлаждения воздуха без применения парокомпрессионных холодильных машин является адиабатическое увлажнение воздуха, т. е. применение камеры орошения на конце вентиляционного трубопровода. Камера состоит из корпуса, внутри которого расположены форсунки, распыляющие воду, каплеуловители и поддон, в который стекает неотработанная вода. При подаче воздуха через камеру распыленная вода начинает испаряться и за счет этого охлаждаться, одновременно охлаждая и увлажняя воздух.

Эффективность способа зависит от относительной влажности воздуха и барометрического давления. Чем выше барометрическое давление и выше относительная влажность воздуха, тем ниже эффективность, и наоборот, чем ниже барометрическое давление и ниже относительная влажность, тем выше их эффективность. Таким образом, если воздух подается с поверхности, эффективность камер орошения в летний период будет ниже, чем в зимний, т. к. летом воздух значительно более влажный, чем зимой. Современ- 
ные камеры орошения позволяют таким способом увлажнить воздух до состояния, когда его относительная влажность будет составлять 85-95\%.

В данном случае воздух подается с поверхности по вентиляционным трубопроводам и нигде не контактирует с водой. Для расчета параметры воздуха приняты по СП 131.13330.2018 [12] для ближайшего населенного пункта города Дудинка и приведены в табл. 2.

Таблица 2. Параметры наружного воздуха

Table 2. Atmosphere parameteres

\begin{tabular}{|c|c|c|c|c|}
\hline $\begin{array}{c}\text { Период года } \\
\text { Season }\end{array}$ & $\begin{array}{c}\text { Температура } \\
\text { Temperature, } \\
{ }^{\circ} \mathrm{C}\end{array}$ & 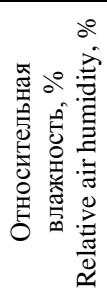 & 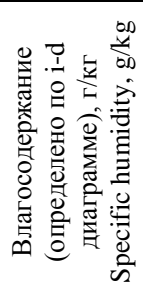 & 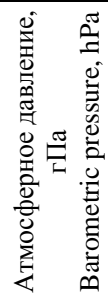 \\
\hline $\begin{array}{c}\text { Зимний } \\
\text { Winter }\end{array}$ & -47 & 74 & 0,04 & \multirow{2}{*}{1011} \\
\hline $\begin{array}{l}\text { Летний } \\
\text { Summer }\end{array}$ & 18,5 & 72 & 9,6 & \\
\hline
\end{tabular}

Далее, по i-d диаграмме влажного воздуха для атмосферного давления было определено влагосодержание воздуха на поверхности, т. к. в отличие от относительной влажности при одинаковой температуре с ростом барометрического давления оно остается одинаковым.

Затем на i-d диаграмму, рассчитанную для барометрического давления, соответствующего глубине -1943 м [17-19], были нанесены процессы изменения состояния влажного воздуха (рис. 4). Процессы 1-3 соответствуют зимнему периоду года, а 4-6 - летнему. Процессы 1, 2 и 4, 5 показывают нагрев воздуха по мере его движения по трубопроводам и для зимнего периода в калориферной, без увлажнения. Процессы 2, 3 и 5, 6 показывают адиабатическое увлажнение воздуха в камере орошения до $90 \%$ относительной влажности.

Результаты построений сведены в табл. 3.

Как видно из табл. 3, в зимний период воздух, подаваемый в забой, является очень сухим, практически с нулевым содержанием влаги, что позволяет его охлаждать с помощью камеры орошения до температуры $19,1{ }^{\circ} \mathrm{C}$. В летний же период, из-за повышения влагосодержания в наружном воздухе, эффективность камеры орошения значительно падает, и температура, до которой она способна охлаждать воздух $\left(27,3^{\circ} \mathrm{C}\right)$, уже превышает предельно допустимое значение.

Таким образом, применение камеры орошения для охлаждения воздуха без применения системы кондиционирования в РВ-2 является наиболее эффективным способом и позволяет обеспечить допустимые температуры воздуха в забое в зимний период, однако в летний период этой меры будет недостаточно. Стоит учесть, что из-за возрастающего влагосодержания в воздухе после его орошения при дальнейшем его нагреве в выработке микроклиматические параметры существенно ухудшаются [20].
Таблица 3. Результаты построения процессов состояния влажного воздуха на i-d диаграмме для давления на глубине -1943 м для летнего и зимнего периода года

Table 3. Results of generation of air irrigation on the $i-d$ diagram for pressure at a depth of -1943 for winter and summer seasons

\begin{tabular}{|c|c|c|c|}
\hline $\begin{array}{c}\text { Toчка } \\
\text { Point }\end{array}$ & $\begin{array}{c}\text { Tемпература } \\
\text { Tempera- } \\
\text { ture, }{ }^{\circ} \mathrm{C}\end{array}$ & $\begin{array}{c}\text { Относитель- } \\
\text { ная влаж- } \\
\text { ность, \% } \\
\text { Relative air } \\
\text { humidity, \% }\end{array}$ & $\begin{array}{c}\text { Влагосодержание } \\
\text { (определено } \\
\text { по i-d диаграмме), г/кг } \\
\text { Specific humidity, g/kg }\end{array}$ \\
\hline \multicolumn{5}{|c|}{ 3имний период/Winter } \\
\hline 1 & -47 & $74 / 97 *$ & 0,04 \\
\hline 2 & 43,7 & 0 & 0,04 \\
\hline 3 & 19,1 & 90 & 9,8 \\
\hline \multicolumn{5}{|c|}{ Летний период/Summer } \\
\hline 4 & 18,5 & $72 / 92^{*}$ & 9,6 \\
\hline 5 & 43,7 & 22 & 9,6 \\
\hline 6 & 27,3 & 90 & 16,2 \\
\hline
\end{tabular}

*Первое значение дано для давления на поверхности, второе - для глубины -1943 м/The first amount is given for surface pressure, the second - for a depth of -1943 m

\section{Применение систем кондиционирования воздуха}

Применение системы кондиционирования воздуха (далее - СКВ), основанной на парокомпрессионных холодильных машинах, позволяет решить большинство вопросов по нормализации микроклимата в выработках, однако является наиболее дорогим решением как в плане капитальных затрат, так и в плане эксплуатационных, поэтому к его применению стараются прибегать только в случае, если другими способами нормализовать микроклимат не удается [21]. Так, согласно произведенным расчетам, для обеспечения температуры подаваемого в забой воздуха, равной $+25^{\circ} \mathrm{C}$, в летний период года необходим кондиционер с холодопроизводительностью 700 кВт.

Из особенностей расчета холодопроизводительности в данном случае стоит обратить внимание на то, что на данной глубине из-за роста барометрического давления температура точки росы значительно возросла. Так, если для воздуха с температурой $43,7^{\circ} \mathrm{C}$ и влагосодержанием 9,6 г/кг температура точки росы составит $14,6{ }^{\circ} \mathrm{C}$, то на глубине 1943 м уже $17,1^{\circ} \mathrm{C}$. Это значит, что при охлаждении воздуха температура точки росы на поверхности воздухоохладителя будет достигнута раньше, а количество конденсируемой влаги увеличится, как следствие возрастает требуемая холодопроизводительность

Поскольку холодильная машина размещается в околоствольном дворе и из-за большой протяженности выработки, требуется прокладка достаточно протяженной трассы с хладоносителем. Согласно расчетам, даже при нанесении 10 мм теплоизоляционного слоя из минеральной ваты потери холода, которые были учтены в расчете, составят порядка 80 кВт. Таким образом, применение СКВ позволяет обеспечить допустимые микроклиматические параметры воздуха в забое круглогодично, однако является наиболее сложным в плане реализации и наиболее дорогим способом. 


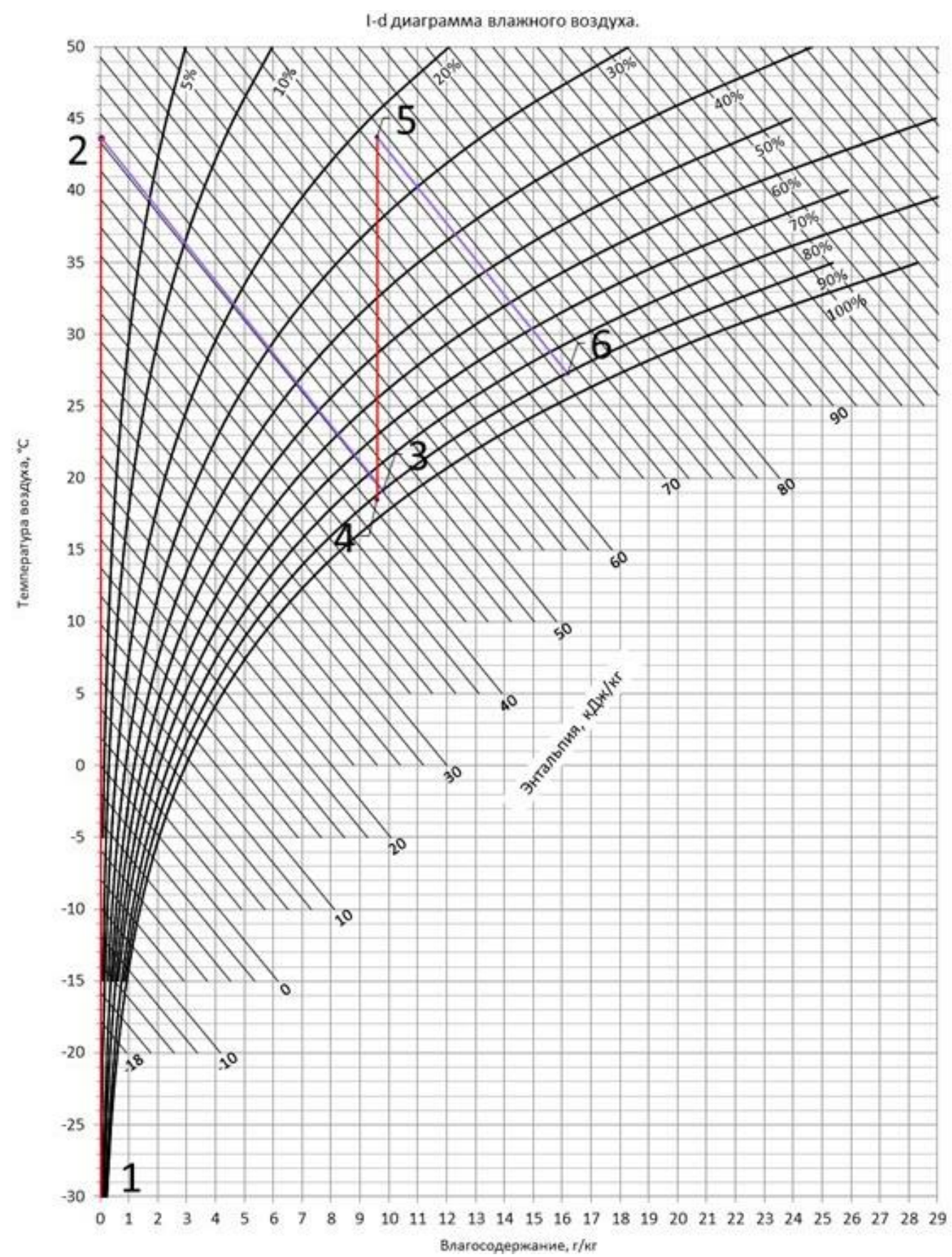

Pис. 4. Результаты построения проиессов состояния влажного воздуха для камеры оромения на і-d диаграмме для давления на глубине -1943 м для летнего и зимнего периода года

Fig. 4. $i$-d diagram for pressure on the depth of $-1943 \mathrm{~m}$ with processes of air irrigation for winter and summer seasons

Результаты расчетов способов нормализации микроклимата в РВ-2 сведены в табл. 4.

Эффективность применения камеры орошения может быть увеличена за счет использования теплоизолированных трубопроводов и увеличения расхода воздуха. Требуемая холодопроизводительность СКВ может быть снижена за счет применения теплоизолированных вентиляционных и циркуляционных трубопроводов. Следует отметить, что при применении СКВ нежелательно вводить мероприятия по увеличению расхода воздуха, поскольку в этом случае требуемая холодильная мощность СКВ существенно воз- растет за счет необходимости охлаждать больший объем воздуха практически до такой же температуры.

\section{Заключение}

Для определения эффективности различных способов снижения температуры воздуха, подаваемого в забой, была разработана математическая модель теплообмена воздуха внутри вентиляционного трубопровода, которая учитывает конвективный и лучистый теплообмен в системе: «воздух в трубопроводе стенка трубопровода - воздух в выработке - породный массив». 
Таблица 4. Результаты расчетов способов нормализации микроклимата

Table 4. Results of numerical simulation for different methods of microclimate normalization

\begin{tabular}{|c|c|c|c|}
\hline \multirow{2}{*}{$\begin{array}{l}\text { Способ снижения температуры } \\
\text { Methods for decreasing air temperature }\end{array}$} & \multicolumn{2}{|c|}{$\begin{array}{l}\text { Температура воздуха в забое } \\
\text { Air temperature near the face, }{ }^{\circ} \mathrm{C}\end{array}$} & \multirow{2}{*}{$\begin{array}{l}\text { Примечание } \\
\text { Note }\end{array}$} \\
\hline & $\begin{array}{l}\text { до охлаждения } \\
\text { before cooling }\end{array}$ & $\begin{array}{l}\text { после охлаждения } \\
\text { after cooling }\end{array}$ & \\
\hline $\begin{array}{l}\text { Увеличение подачи воздуха } \\
\text { Air flowrate increase }\end{array}$ & \multirow{8}{*}{43,7} & 43,0 & $\begin{array}{l}\text { Не эффективно } \\
\text { Not effective }\end{array}$ \\
\hline $\begin{array}{l}\text { Теплоизолированные трубопроводы (20 мм) } \\
\text { Thermally insulated duct (20 mm) }\end{array}$ & & 37,1 & \multirow{4}{*}{$\begin{array}{c}\text { Неэффективно, не требует } \\
\text { эксплуатационных затрат } \\
\text { Not effective, no operating costs }\end{array}$} \\
\hline $\begin{array}{l}\text { Теплоизолированные трубопроводы (50 мм) } \\
\text { Thermally insulated duct }(50 \mathrm{~mm})\end{array}$ & & 32,9 & \\
\hline $\begin{array}{l}\text { Теплоизолированные трубопроводы (100 мм) } \\
\text { Thermally insulated duct (100 mm) }\end{array}$ & & 30,4 & \\
\hline $\begin{array}{l}\text { Теплоизолированные трубопроводы (150 мм) } \\
\text { Thermally insulated duct (150 mm) }\end{array}$ & & 29,4 & \\
\hline $\begin{array}{l}\text { Применение оросителей воздуха (летом) } \\
\text { Air irrigation (summer) }\end{array}$ & & 27,3 & \multirow{2}{*}{$\begin{array}{c}\text { Эффективно в зимний период, } \\
\text { неэффективно в летний } \\
\text { Effective in winter, not effective in summer }\end{array}$} \\
\hline $\begin{array}{l}\text { Применение оросителей воздуха (зимой) } \\
\text { Air irrigation (winter) }\end{array}$ & & 19,1 & \\
\hline $\begin{array}{l}\text { Применение СКВ } \\
\text { Air conditioning }\end{array}$ & & 25 & $\begin{array}{c}\text { Эффективно. Требует больших капи- } \\
\text { тальных и эксплуатационных затрат } \\
\text { Effective. High capital and operating costs }\end{array}$ \\
\hline
\end{tabular}

Были исследованы различные способы снижения температуры воздуха, подаваемого в забой, в глубокой тупиковой выработке большой протяженности, такие как: увеличение объема подачи воздуха в забой, покрытие теплоизоляцией вентиляционных труб, охлаждение воздуха с помощью камеры орошения и применение системы кондиционирования воздуха. В результате проведенных расчетов было определено, что увеличение расхода воздуха и применение теплоизолированных трубопроводов не обеспечивает допустимые микроклиматические параметры в забое PB-2.

\section{СПИСОК ЛИТЕРАТУРЫ}

1. Normalization of thermal mode of extended blind workings operating at high temperatures based on mobile mine air conditioners, St. Peterburg, Russia / V.R. Alabyev, V.V. Novikov, L.A. Pashinyan, T.P. Bazhina // Journal of Mining Institute. 2019. - V. 237. - P. 251-258

2. Potential sources of heat in underground mines - a review/ M. Tripti, K. Kailash, H. Vardhan, M. Aruna, M.G. Raj // Procedia Earth Planet Science. - 2015. - V. 11. - P. 463-468.

3. Implementing a DIKW model on a deep mine cooling system $/$ J.G. Pretorius, M.J. Mathews, P. Mare, M. Kleingeld, J. Rensburg // International Journal of Mining Science and Technology. - 2019. V. 29. - № 2. - P. 319-326.

4. Design and evaluation of cooling workwear for miners in hot underground mines using PCMs with different temperatures, Warszawa, Polska / Q. Zheng, Ying Ke, H. Wang // International Journal of Occupational Safety and Ergonomics. - 2020. V. 26. - P. 1-11.

5. Кормщиков Д.С., Попов М.Д., Нормализация теплового режима глубоких залежей рудника «Таймырский» до момента ввода системы кондиционирования // Горное Эхо. Пермь. 2019. - № 2. - С. 92-96.

6. Особенности формирования микроклиматических условий в горных выработках глубоких рудников / В.Н. Карелин, А.В. Кравченко, Л.Ю. Левин, Б.П. Казаков, А.В. Зайцев // Горный журнал. - 2013. - № 6. - С. 65-68.

7. Казаков Б.П., Зайцев А.В. Исследование процессов формирования теплового режима глубоких рудников // Вестник Пермского национального исследовательского политехнического университета. - 2014. - № 10. - С. 91-97.

8. Федеральные нормы и правила в области промышленной безопасности «Правила безопасности при ведении горных работ и переработке твердых полезных ископаемых»: утв. приказом
Охлаждение воздуха с помощью камеры орошения позволяет обеспечить допустимую температуру воздуха в зимний период, но не позволяет обеспечить её в летний период. Применение СКВ является единственным способом достижения допустимых микроклиматических параметров в забое выработки, однако является самым дорогим и технически сложным способом.

Исследование выполнено при финансовой поддержке Российского научного фонда в рамках проекта № 19-77-30008.

Ростехнадзора от 08.12.2020 № 505. - М.: Изд-во «Центрамаг», 2020. $-122 \mathrm{c}$

9. Analysis of thermal regime of a deep mine airway in permafrost, London, GB / S. Bandopadhyay, H. Wu, M.G. Nelson, V. Izaxon // Mining in the Arctic. - 2001. - V. 1. - P. 107-117.

10. Roghanchi P., Kocsis K.C. Quantifying the thermal damping effect in underground vertical shafts using the nonlinear autoregressive with external input (NARX) algorithm // International Journal of Mining Science and Technology. - 2019. - V. 2. - P. 255-262.

11. Semin M., Zaitsev A. On a possible mechanism for the water build-up formation in mine ventilation shafts // Thermal Science and Engineering Progress. - 2020. - № 5. - P. 1-7.

12. СП 131.13330.2018 Строительная климатология. Актуализированная редакция СНиП 23-01-99*: утв. приказом Министерства регионального развития от 28.11.2018 № 275. - М.: Изд-во «Стандартинформ», 2019. - 114 с .

13. McPherson M.J. The analysis and simulation of heat flow into undergrounds airways // International Journal of Mining and Geological Engineering. - 1986. - V. 4. - P. 165-196.

14. Шалимов А.В. Теоретические основы прогнозирования, профилактики и борьбы с аварийными нарушениями проветривания рудников. - Пермь: Изд-во ГИ УрО РАН, 2012. - 329 с.

15. Бухмиров В.В. Расчет коэффициента конвективной теплоотдачи (справочник). - Иваново: ИГЭУ, 2007. -39 с.

16. Казаков Б.П. Методика расчета требуемого количества воздуха для проветривания подземных горных выработок месторождения Октябрьское. - Пермь: Изд-во «ГИ УрО РАН», 2017. $-78 \mathrm{c}$.

17. Нестеренко А.В. Основы термодинамических расчетов вентиляции и кондиционирования воздуха. - М.: Высшая школа, 1971. $-460 \mathrm{c}$

18. Богословский В.Н., Кокорин О.Я., Петров Л.В. Кондиционирование воздуха и холодоснабжение. - М.: Стройиздат, 1985. $-367 \mathrm{c}$. 
19. Стефанов Е.В. Вентиляция и кондиционирование воздуха. Л.: ВВИТКУ, 1970. - 399 c.

20. Effects of thermal water upwelling on microclimate change in the high geo-temperature roadway / W. Junhui, W. Zhijun, Z. Hongwei, W. Jingchao, W. Yi, Z. Yuan, L. Sifei, L. Ning // Shock and Vibration. - 2021. - V. 2021. - P. 1-14.
21. Mackay L., Bluhm S., Van Rensburg J. Refrigeration and cooling concepts for ultra-deep platinum mining // Boom or Bust: The 4th International Platinum Conference, Platinum in transition. - Sun City, Rustenburg, South Africa: The Southern African Institute of Mining and Metallurgy, 2010. - P. 285-292.

Поступила 08.12.2021 2.

\section{Информация об авторах}

Ольховский Д.В., инженер Горного института уральского отделения российской академии наук.

Зайцев A.B., доктор технических наук, заведующий сектором горной теплофизики Горного института уральского отделения российской академии наук.

Шалимов A.B., доктор технических наук, ведущий научный сотрудник Горного института уральского отделения российской академии наук.

Давыдов А.А., руководитель проектного офиса комплексного развития рудника Скалистый ПАО «ГМК "Норильский Никель"». 
UDC 622.413 .4

\title{
METHODS FOR MICROCLIMATE NORMALIZATION IN DEEP LONG BLIND DRIFTS
}

\author{
Dmitriy V. Olkhovskiy ${ }^{1}$ \\ demexez@gmail.com
}

\author{
Artem V. Zaytsev'1, \\ aerolog.artem@gmail.com
}

Andrey V. Shalimov ${ }^{1}$, aerolog.artem@gmail.com

\author{
Andrey A. Davydov², \\ Davydovaa@nornik.ru \\ 1 Mining Institute of the Ural Branch of the Russian Academy of Sciences, \\ 78a, Sibirskaya strret, Perm, 614007, Russia. \\ 2 PJSC «MMC "Norilsk Nickel"», \\ 15, 1st Krasnogvardeysky secondary street, Moscow, 123100, Russia.
}

The relevance of the research is provided by the complexity of microclimate normalization in long blind drifts which are driven deeply through geothermally heated rocks.

The aim of the research is the evaluation of usability of different ways for microclimate normalization in the working section of the exploration drift-2 in the mine of PJSC «MMC "Norilsk Nickel"».

Objects: the exploration mine exploration drift-2 of PJSC «MMC "Norilsk Nickel"».

Methods: the numerical simulation of heat and mass transfer in the atmosphere of the long exploration drift, the comparative analysis of simulation results.

Results. The paper reviews ways, comparing their features, advantages, and disadvantages, for microclimate normalization in deep blind drifts. The presented mathematical model describes the heat and mass transfer in the working section of the blind drift with ventilation through the air duct. The model considers convective and radiant heat transfers. The results of the numerical simulation are given for different air-cooling methods which are applicable in the case of the deep copper-nickel mine of PJSC "MMC "Norilsk Nickel"». Drawing on this, different mining and thermal engineering operations for normalization of air temperatures in the working section regarding safety requirements are compared. It is defined that increasing the intake air flowrate could not decrease the air temperature near the face. The use of thermally insulated duct significantly decreases the air temperature in the working section but does not reduce it to the permitted value. It is shown, that the air irrigation could normalize temperatures in winter and not during the summer months. Underground air conditioning is the most universal and effective way for this purpose but highly expensive.

Key words:

Blind drifts, deep mine, microclimate, air irrigation, thermal insulation, air conditioning, air duct.

The research was financially supported by the Russian Science Foundation within the project no. 19-77-30008.

\section{REFERENCES}

1. Alabyev V.R., Novikov V.V., Pashinyan L.A., Bazhina T.P. Normalization of thermal mode of extended blind workings operating at high temperatures based on mobile mine air conditioners, St. Peterburg, Russia. Journal of Mining Institute, 2019, vol. 237, pp. 251-258.

2. Tripti M., Kailash K., Vardhan H., Aruna M., Raj M.G. Potential sources of heat in underground mines - a review. Procedia Earth Planet Science, 2015, vol. 11, pp. 463-468.

3. Pretorius J.G., Mathews M.J., Mare P., Kleingeld M., Rensburg J. Implementing a DIKW model on a deep mine cooling system. International Journal of Mining Science and Technology, 2019, vol. 29, no. 2, pp. 319-326.

4. Ying Ke Q.Z., Wang H. Design and evaluation of cooling workwear for miners in hot underground mines using PCMs with different temperatures, Warszawa, Polska. International Journal of Occupational Safety and Ergonomics, 2020, vol. 26, pp. 1-11.

5. Kormshchikov D.S., Popov M.D., Normalizatsiya teplovogo rezhima glubokikh zalezhey rudnika «Taymyrskiy» do momenta vvoda sistemy konditsionirovaniya [Normalization of the thermal behavior of deep deposits of the Taimyrskiy, mine before the commissioning of the air conditioning system]. Mountain echo, 2019, no. 2, pp. 92-96.
6. Karelin V.N., Kravchenko A.V., Levin L.Yu., Kazakov B.P., Zaytsev A.V. Osobennosti formirovaniya mikroklimaticheskikh usloviy v gornykh vyrabotkakh glubokikh rudnikov [Features of the formation of microclimatic conditions in the mine workings of deep mines]. Mining journal, 2013, no. 6, pp. 65-68.

7. Kazakov B.P., Zaytsev A.V. Issledovanie protsessov formirovaniya teplovogo rezhima glubokikh rudnikov [Studies of the formation processes of the thermal regime of deep mines]. Bulletin of the Perm National Research Polytechnic University, 2014, no. 10, pp. 91-97.

8. Federalnye normy i pravila $v$ oblasti promyshlennoy bezopasnosti «Pravila bezopasnosti pri vedenii gornykh rabot i pererabotke tverdykh poleznykh iskopayemykh» [Federal norms and rules in the field of industrial safety «Safety rules for mining and processing of solid minerals»]. Approved by order Rostekhnadzora dated 08.12.2020 no. 505. Moscow, Tsentramag Publ., 2020. 122 p.

9. Bandopadhyay S., Wu H., Nelson M.G., Izaxon V. Analysis of thermal regime of a deep mine airway in permafrost, London, GB. Mining in the Arctic, 2001, vol. 1, pp. 107-117.

10. Roghanchi P., Kocsis K. C. Quantifying the thermal damping effect in underground vertical shafts using the nonlinear autoregressive with external input (NARX) algorithm. International Journal of Mining Science and Technology, 2019, vol. 2, pp. 255-262. 
11. Semin M., Zaytsev A. On a possible mechanism for the water build-up formation in mine ventilation shafts. Thermal Science and Engineering Progress, 2020, vol. 5, pp. 1-7.

12. SP 131.13330.2018 Stroitelnaya klimatologiya [Building climatology]. Approved by order of the Ministry of Regional Development dated 28.11.2018, no. 275. Moscow, Standartinform Publ., 2019. $114 \mathrm{p}$.

13. McPherson M.J. The analysis and simulation of heat flow into undergrounds airways. International Journal of Mining and Geological Engineering, 1986, vol. 4, pp. 165-196.

14. Shalimov A.V. Teoreticheskie osnovy prognozirovaniya, profilaktiki i borby s avariynymi narusheniyami provetrivaniya rudnikov [Theoretical foundations of programming for prevention and combating emergency violations of mine ventilation]. Perm, MI UB RAS Publ., 2012. 329 p.

15. Bukhmirov V.V. Raschet koeffitsiyenta konvektivnoy teplootdachi (spravochnik) [Calculation of the convective heat transfer coefficient (reference book)]. Ivanovo, IGEU Publ., 2007. 39 p.

16. Kazakov B.P. Metodika rascheta trebuyemogo kolichestva vozdukha dlya provetrivaniya podzemnykh gornykh vyrabotok mestorozhdeniya Oktyabrskoe [Methodology for calculating the air demand for ventilating underground mine workings of the Oktyabrskoe deposit]. Perm, MI UB RAS Publ., 2017. 78 p.
17. Nesterenko A.V. Osnovy termodinamicheskikh raschetov ventilyatsii $i$ konditsionirovaniya vozdukha [Fundamentals of thermodynamic calculations for ventilation and air conditioning]. Moscow, Vysshaya shkola Publ., 1971. 460 p.

18. Bogoslovskiy V.N., Kokorin O.Ya., Petrov L.V. Konditsionirovanie vozdukha $i$ kholodosnabzhenie [Air conditioning and refrigeration]. Moscow, Stroyizdat Publ., 1985. 367 p.

19. Stefanov E.V. Ventilyatsiya i konditsionirovanie vozdukha [Ventilation and air conditioning]. Leningrad, HMETRBS Publ., 1970. $399 \mathrm{p}$.

20. Junhui W., Zhijun W., Hongwei Z., Jingchao W., Yi W., Yuan Z., Sifei L., Ning L. Effects of thermal water upwelling on microclimate change in the high geo-temperature roadway. Shock and Vibration, 2021, vol. 2021, pp. 1-14.

21. Mackay L., Bluhm S., Van Rensburg J. Refrigeration and cooling concepts for ultra-deep platinum mining. The 4th International Platinum Conference, Platinum in transition. Boom or Bust. Sun City, Rustenburg, South Africa, The Southern African Institute of Mining and Metallurgy, 2010. pp. 285-292.

Received: 8 December 2021.

\section{Information about the authors}

Dmitriy V. Olkhovskiy, engineer, Mining Institute of the Ural Branch of the Russian Academy of Sciences.

Artem V. Zaytsev, Dr. Sc., head of the Mining Thermal Physics Sector, Mining Institute of the Ural Branch of the Russian Academy of Sciences.

Andrey V. Shalimov, Dr. Sc., leading research worker, Mining Institute of the Ural Branch of the Russian Academy of Sciences.

Andrey A. Davydov, head of the project office for the integrated development of the Skalisty mine, «MMC "Norilsk Nickel"». 